\title{
JUSTIFICATION OF FINANCIAL SAFETY ANALYSIS APPROACH IN CARGO-AND-PASSENGER FERRY OPERATIONS MANAGEMENT
}

\author{
Yelena V. Kirillova ${ }^{1}$, Yekaterina S. Meleshenko ${ }^{2}$ \\ Odessa National Maritime University \\ Department of "MarineTtransportation" \\ Mechnikov Str. 34, 65029, Odessa, Ukraine \\ Phone: ${ }^{1}+380674805277,{ }^{2}+380930699061$ \\ E-mail: ${ }^{1}$ kirillova@matrix.odessa.ua, ${ }^{2}$ kat_meleshenko@mail.ru
}

Currently, ferry services are widespread in Europe, the Baltic States, the CIS and they continue to progress rapidly despite the unstable global economy. An activity of modern cargo-and-passenger fleet is based on nevertheless the perspective of stable profit generation. In conditions of ferry market instability, the important task is to ensure the break-even analysis in operation of vessels and justification of relevant quantitative indicators. At the same time, when managing the production activity of the ferry operators and, in particular, when analysing the ferry operation the indicator of its financial safety factor is of great importance.

This paper refines static indicators and determines dynamic indicators of critical quantity of cargoes and passengers in ferry loading; gives analytical method of its justification; develops analytical method and presents graphical method of financial safety factor estimation when loading of cargo only or boarding of passengers only, as well as performing composite actions - loading of cargoes and picking up passengers.

Keywords: ferry transportation, cargo-and-passenger ferry, dynamic indicators, critical loading, financial safety factor

\section{Introduction}

The ferry service is an important part of the transport process in the system of international freight and passenger transportation. Currently, ferry services are widespread in Europe, the Baltic States, the CIS and they continue to progress rapidly despite the unstable global economy.

The Black Sea countries provide transport and economic links in the west-east and north-south by ferries. Ferries of this region provide transportation of freight vehicles between Ukraine, Georgia, Turkey, Bulgaria, Romania and Russia. The most popular ferry transportation destinations in Ukraine are Kerch Poti/Batumi, Odessa-Istanbul, Illichevsk -Batumi/Poti. The main participant in the Ukrainian Black Sea ferry market is the company "Ukrferry", which has the status of a national carrier in Ukraine.

The functioning of "Ukrferry", as well as activities of other carriers, is currently carried out in the consumer market (cargo and/or passenger), where transport supply exceeds the demand. In such a situation it is actually for the companies operating in the sphere of ferry traffic to develop an appropriate, adapted to the market characteristics, methodological support of decision-making processes for organization of ferry traffic and ferries management. One of the powerful tools for solving numerous administrative tasks related with the production activities of the shipping companies in the consumer market is a break-even analysis. It helps the ship owner, who seeks to make a profit under all the circumstances, do not lose sight of performance equilibrium quantities of individual vessels and a fleet as a whole. The practical realization of break-even analysis can justify such a critical level of transport production by which the revenues of company are equal to its costs. The break-even analysis also helps to justify the reasonability of (Kirillova \& Kirillov, 2008):

- transportation of cargo which quantity is less than vessel manufacturing feasibility;

- discounting to cargo owners and/or tariff reductions;

- inclusion the port to the list of essential ones when designing the new shipping line;

- entering the vessel to the optional port of the existing line, etc.

The methodologies determining a break-even analysis in operations of the marine transport are presented in many sources. Thus, the sources (Vinnicov, 2001; Soyuzov \& etc., 1979; Bakayev, 1965) state the composition and the procedure of forming the marine transport costs, method of their calculations and use by type of proceedings, the tasks of pricing and finances of the shipping company, the features of estimation of shipping companies economic activities in market conditions. The reports 
(Kirillova, 2007; Kirillova \& Meleshenko, 2012) formulate the provisions on justification of critical and commercially reasonable loading of cargo and passenger vessels, based on the method of break-even analysis. The works (Kirillova \& Kirillov, 2008; Kirillova, 2006) develop the regulations on justification of optimal values of cargo vessel operation indicators using the method of marginal analysis. However, the systems of indicators presented in these sources do not take into account the possibility of a composite vessel loading with goods under different nomenclature ranges and passengers, which is not only widely practiced in cargo-and-passenger ferries, but is their specific feature. The science sources (Kirillova \& Meleshenko, 2013a; Kirillova \& Meleshenko, 2013b; Kirillova \& Meleshenko, 2013c) propose the analytical method of determining the values of dynamic indicators of critical loading and operation of a cargo-and-passenger ferry. However, it is obvious that the actual size of the critical production of the transport is not an objective measure for different-sized vessels especially from the position of a comparative analysis of their activity as the volume of cargo transportation by these vessels is different. In this connection, it is necessary to justify such an indicator, which, regardless of the technical and operational vessel characteristics, allows understanding how much percent one can reduce the amount of transportation services (shipments) on for reaching the loss-free ship operation. This indicator is "the ratio of financial safety" evaluated in percentages. The indicators presented in abovementioned sources do not include the ratio of financial safety that stipulates the necessity of the additional research.

Thereby, the aim of the study is to improve the method of determining the break-even analysis in operations of cargo-and-passenger ferry through the development of theoretical and methodological principles on justification of its financial safety factor.

\subsection{Theoretical aspects}

The main production of shipping company operating cargo-and-passenger ferry is the multinomenclature because the transportation facilities are cargoes and passengers. This fact makes it necessary to take into account the parameters of freight and passenger traffic to justify the decisions related to the organization of the ferry transportation and management of ferries. The importance in the consumer market, as mentioned above, gets a break-even analysis. During its realization the static indicators of critical ferry loading with cargoes $\left(N_{i}^{c r}\right)$ and passengers $\left(N_{\text {pass }}^{c r}\right)$ can be easily defined under the provisions formulated in (Kirillova \& Kirillov, 2008):

$$
\begin{aligned}
& N_{i}^{c r}=\frac{R_{f i x}}{f_{i}-r_{i}}\left(\text { at } f_{i}-r_{i} \neq 0\right) ; \\
& \left.N_{\text {pass }}^{c r}=\frac{R_{\text {fix }}}{f_{\text {pass }}-r_{\text {pass }}} \text { (at } f_{\text {pass }}-r_{\text {pass }} \neq 0\right),
\end{aligned}
$$

where $R_{f i x}$ - fixed costs applied to the ship in the concerned voyage. They include direct fixed costs (depreciation, agent fees, the cost of loan repayments, crew maintenance, insurance, repairs, supplies, etc.) and indirect fixed (administrative management and general operational) costs;

$f_{i} ; f_{\text {pass }}$ - rate for carriage the cargo of the $i^{\text {th }}$ nomenclature range and, accordingly, the price of passenger tickets;

$r_{i} ; r_{\text {pass }}-$ unit variable costs for transportation the cargo of the $i^{\text {th }}$ nomenclature range and for maintenance of one passenger. They include fuel and lubricants costs, port, channel, mooring, pilotage, towing and other fees, charges for freight operations, brokerage commissions and other variable costs depending on the value of the vessel operation.

In general, the composition of fixed and variable costs is determined by the decision maker (DM), depending on the purpose of the analysis and the form of ship operation organization. Thus, the static indicators of critical ferry loading are defined separately for cargoes $\left(N_{i}^{c r}\right)(1)$, separately for passengers $\left(N_{\text {pass }}^{c r}\right)$ (2) and are independent from each other. At the same time, it is obvious that cargo-andpassenger ferries combine the properties of the cargo vessels and the passenger vessels; hence the efficiency of their operation is specified by both the amount of cargoes and the number of passengers 
in the ship loading. It requires the elaboration and justification of another approach to the break-even analysis of production activity of shipping companies operating cargo-and-passenger ferries.

Different ferry spaces (rooms) are intended for cargoes and passengers, namely the cargo decks are for goods; cabins are for passengers. This enables the simultaneous consideration of cargo and passenger flow parameters in relation to each other despite the different dimension of indicators granting their quantitative assessment.

The indicators reflecting the amount of cargoes and passengers in ferry loading have an impact on the economic results of its operation. As the applications for the cargo transportation are being received from cargo owners and/or as the tickets are being bought by passengers, the information about their quantity is updated at the certain intervals (once a day, once in 3 days, etc.). On the ground of the received information the step-by-step adjustment of relevant functionally dependent targets is made. The period of information clarification and, hence, the interval of data correction is set by DM. Thus, the values of planned targets are corrected in each step $t$ of the decision-making, which corresponds to the certain period of refinement and updating of data about cargoes $\left(N_{i}^{(t)}\right)$ volume and passengers $\left(N_{\text {pass }}^{(t)}\right)$ number on the grounds of:

- the information stated in the newly received applications from the cargo owners;

- the information about the newly purchased tickets by passengers.

Therefore, at step-by-step decision-making related to the justification of cargo-and-passenger ferry operation in the consumer market conditions, it is proposed to use the following interrelated and interdependent dynamic indicators of the critical vessel loading:

- the critical quantity of cargoes $\left(N_{i}^{c r(t)}\right)$;

- the critical number of passengers $\left(N_{\text {pass }}^{c r(t)}\right)$.

The dynamic indicators of critical cargo-and-passenger ferry loading reflect such a minimum quantity of cargoes $\left(N_{i}^{c r(t)}\right)$ and passengers $\left(N_{\text {pass }}^{c r(t)}\right)$ in composite vessel loading during the development of which the company' costs $\left(R^{(t)}\right)$ in step $t$ of decision-making are compensated by its income $\left(F^{(t)}\right)$. As a rule, in the situation of the consumer market ensuring of the full utilization of ferry manufacturing feasibilities caused by its technical characteristics is not possible. In this regard the fulfilment of the conditions is a prime consideration (3) (Kirillova \& Meleshenko, 2013b).

$\left.\begin{array}{l}N_{i}^{(t)}>N_{i}^{c r(t)}(i \in I) ; \\ N_{\text {pass }}^{(t)}>N_{\text {pass }}^{c r(t)} .\end{array}\right\}$,

where $N_{i}^{(t)}$ - the quantity of the $\mathrm{i}^{\text {th }}$ nomenclature range cargo planned to transportation that was refined in step $t$ of decision-making;

$N_{\text {pass }}^{(t)}$ - the number of passengers planned to transportation and service in voyage that was refined in step $t$ of decision-making;

$N_{i}^{c r(t)} ; N_{\text {pass }}^{c r(t)}$ - the critical quantity of the $i^{\text {th }}$ nomenclature range cargo and, accordingly, the passengers corrected in step $t$;

$I$ - the set of cargo nomenclature ranges planned for the carriage (automobile equipment, rail buses, containers, etc.).

The restrictions (4) regulate the cargo-and-passenger ferry operation in accordance with its specifications (Kirillova \& Meleshenko, 2013b).

$\left.\begin{array}{l}N_{i}^{(t)} \leq N_{i}^{\max }(i \in I) \\ N_{\text {pass }}^{(t)} \leq N_{\text {pass }}^{\max } .\end{array}\right\}$,

where $N_{i}^{\max }$ - the maximum possible quantity of the $i^{\text {th }}$ nomenclature range cargo which could be taken on board in accordance with its specifications;

$N_{\text {pass }}^{\max }$ - the maximum possible number of passengers (including persons accompanying the cargo, drivers of the transported cars) that the vessel can take on board in accordance with its passenger capacity. 
The restrictions (4) acquire a priority in situation of the ship owner market, when the demand for ferry services exceeds their supply and the desire to maximize the loading of the vessel is limited by its technical capabilities. However, the consumer market does not exclude the need to comply with the given group of limits. Thus, the ferry cargoes and passengers carriage is break-even under the conditions (2) and (4) (Kirillova \& Meleshenko, 2013b):

$$
\left.\begin{array}{l}
N_{i}^{c r(t)}<N_{i}^{(t)} \leq N_{i}^{\max }(i \in I) \\
N_{\text {pass }}^{c r(t)}<N_{\text {pass }}^{(t)} \leq N_{\text {pass }}^{\max } .
\end{array}\right\}
$$

Let us consider the order of the analytical justification of indicators $N_{i}^{c r(t)}$ and $N_{\text {pass }}^{c r(t)}$.

The ferry operation in step $\mathrm{t}$ of decision-making is a break-even subject to the following equation: $F^{(t)}=R^{(t)}$, which may be refined as follows (Kirillova \& Meleshenko, 2013b):

$$
\begin{aligned}
& F^{(t)}=N_{i}^{(t)} \cdot f_{i}+N_{\text {pass }}^{(t)} \cdot f_{\text {pass }}, \\
& R^{(t)}=R_{\text {fix }}+N_{i}^{(t)} \cdot r_{i}+N_{\text {pass }}^{(t)} \cdot r_{\text {pass }}, \\
& N_{i}^{(t)} \cdot f_{i}+N_{\text {pass }}^{(t)} \cdot f_{\text {pass }}=R_{\text {fix }}+N_{i}^{(t)} \cdot r_{i}+N_{\text {pass }}^{(t)} \cdot r_{\text {pass }} .
\end{aligned}
$$

On the ground of equation (8) it the critical quantity of the $\mathrm{i}^{\text {th }}$ nomenclature range cargo $\left(N_{i}^{c r(t)}\right)$ could be determined, it provides a break-even analysis for operations management in step $\mathrm{t}$ of decisionmaking (Kirillova \& Meleshenko, 2013b):

$$
N_{i}^{c r(t)}=\frac{R_{f i x}-N_{p a s s}^{(t)} \cdot\left(f_{\text {pass }}-r_{\text {pass }}\right)}{f_{i}-r_{i}}\left(\text { at } f_{i}-r_{i} \neq 0\right)
$$

Similarly to the indicator of the critical quantity of cargoes $\left(N_{i}^{c r(t)}\right)(9)$, the critical number of passengers $\left(N_{\text {pass }}^{c r(t)}\right)$ could be determined in step t (Kirillova \& Meleshenko, 2013b)

$$
N_{\text {pass }}^{c r(t)}=\frac{R_{f i x}-N_{i}^{(t)} \cdot\left(f_{i}-r_{i}\right)}{f_{\text {pass }}-r_{\text {pass }}}\left(\text { at } f_{\text {pass }}-r_{\text {pass }} \neq 0\right) \text {. }
$$

The considered indicators of the critical quantity of cargoes $\left(N_{i}^{c r(t)}\right)$ and the critical number of passengers $\left(N_{\text {pass }}^{c r(t)}\right)$ are expressed in physical terms. However, these indicators are not objective when comparing the different-sized vessels, which volume of traffic differs in scores of times. Thus, besides the above-mentioned indicators of the critical quantity of cargoes $\left(N_{i}^{c r(t)}\right)$ and the critical number of passengers $\left(N_{\text {pass }}^{c r(t)}\right)$ when calculating break-even point in ferry operation, the ratio of financial safety expressed in percentage is proposed. The calculation of this ratio is proposed to be carried out in each step $\mathrm{t}$ of defining the information about the quantity of cargoes declared to transportation and the number of sold passenger tickets. The ratio of financial safety demonstrates the share which can reduce the amount of the transport services provision so that the company does not incur losses. The standard value of this indicator is set by DM, depending on the condition of the ferry transportation market, for example $10 \%\left(k_{i}^{F S(t)} \geq 10 \%\right)$. 
The ratio of financial safety in each step $\mathrm{t}$ of decision-making when loading the ferry with cargoes $\left(k_{i}^{F S(t)}\right)$ and passengers $\left(k_{\text {pass }}^{F S(t)}\right)$ is easily determined on the basis of provisions set in the book (Stoyanova, 2003):

$$
\begin{aligned}
& k_{i}^{F S(t)}=\frac{\left(N_{i}^{(t)}-N_{i}^{c r}\right)}{N_{i}^{(t)}} \cdot 100 \%\left(\text { at } N_{i}^{(t)} \neq 0\right) ; \\
& k_{\text {pass }}^{F S(t)}=\frac{\left(N_{\text {pass }}^{(t)}-N_{\text {pass }}^{c r}\right)}{N_{\text {pass }}^{(t)}} \cdot 100 \%\left(\text { at } N_{\text {pass }}^{(t)} \neq 0\right) .
\end{aligned}
$$

The analytical expression mentioned above (11), (12) can be graphically described using the twodimensional coordinate system. Thus, the ratio of financial safety in providing the cargo transportation services $\left(k_{i}^{F S(t)}\right)$ at a constant value $\left(N_{i}^{c r}\right)$ depends on the quantity of the carried cargoes $\left(N_{i}^{(t)}\right)(11)$, i.e. it is a function of respective argument:

$y=f(x)$

$$
k_{i}^{F S(t)}=f\left(N_{i}^{(t)}\right)=\frac{\left(N_{i}^{(t)}-N_{i}^{c r}\right)}{N_{i}^{(t)}} \cdot 100 \% .
$$

\subsection{Graphical visualization in two- and three-dimensional coordinate systems}

The graphic of this function is a curve, illustrated in the two-dimensional space. Therefore, when visualizing graphically the task of determining the ratio of financial safety, it is appropriate to use a righthanded two-dimensional coordinate system (Fig. 1), formed by the mutually perpendicular axes:

- by $\mathrm{X}$-axis - $O X$, corresponding to the axis $O N_{i}$ in this case;

- by Y-axis - $O Y$, corresponding to the axis $O k^{F S}$.

The maximum value of the ratio for the cargo ship $\left(k_{i}^{F S(\max )}\right)$ is achieved with the maximum amount of cargoes $\left(N_{i}^{\max }\right)$ on board, which, in turn, is limited by the technical characteristics of the vessel (capacity, tonnage, container capacity and passenger capacity).

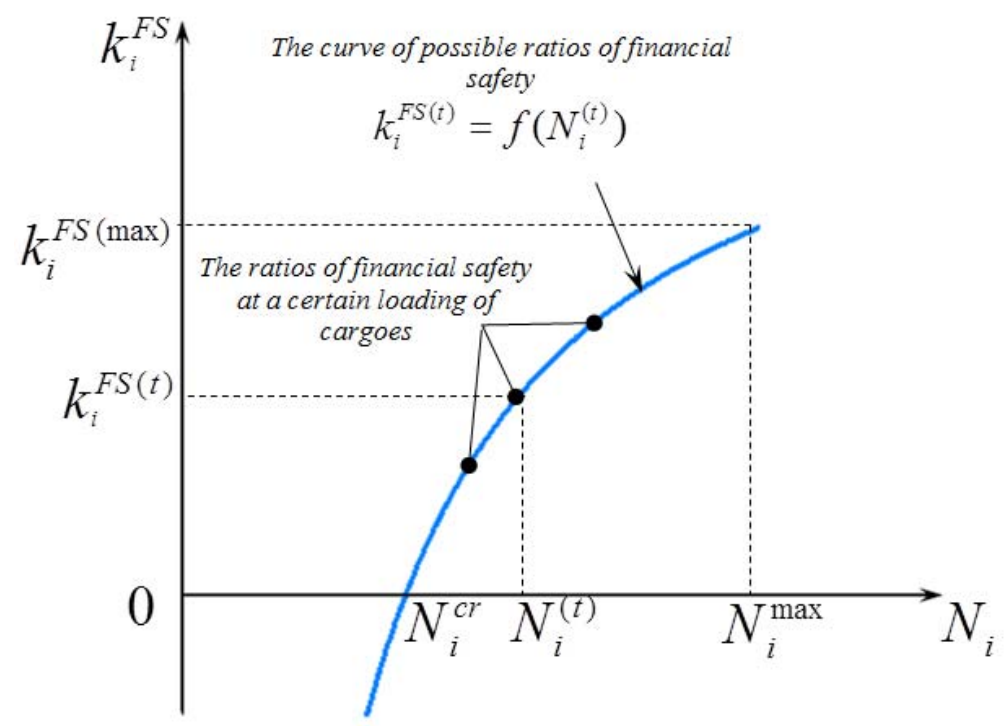

Figure 1. The ratio of financial safety when transporting the cargoes, determined through the quantity of cargoes, $\%$ 
Each point of the curve expresses the proportion to which the company can reduce the amount of cargo transportation services so that it does not incur losses. That is, when reducing the amount of cargoes on the quantity equal to $\left(k_{i}^{F S} \cdot N_{i}\right)$, the company will make a profit $\left(\operatorname{Pr}_{i}\right)$ from the transportation of goods equal to zero. At $\left(N_{i}=N_{i}^{c r}\right)$ the financial safety ratio $\left(k_{i}^{F S}\right)$ possesses the value equal to zero: $k_{i}^{F S}=0$.

The similar arguments can be made in respect to the financial safety ratio when transporting the passengers $\left(k_{\text {pass }}^{F S}\right)$, which is a function of $N_{\text {pass }}$ (Fig. 2).

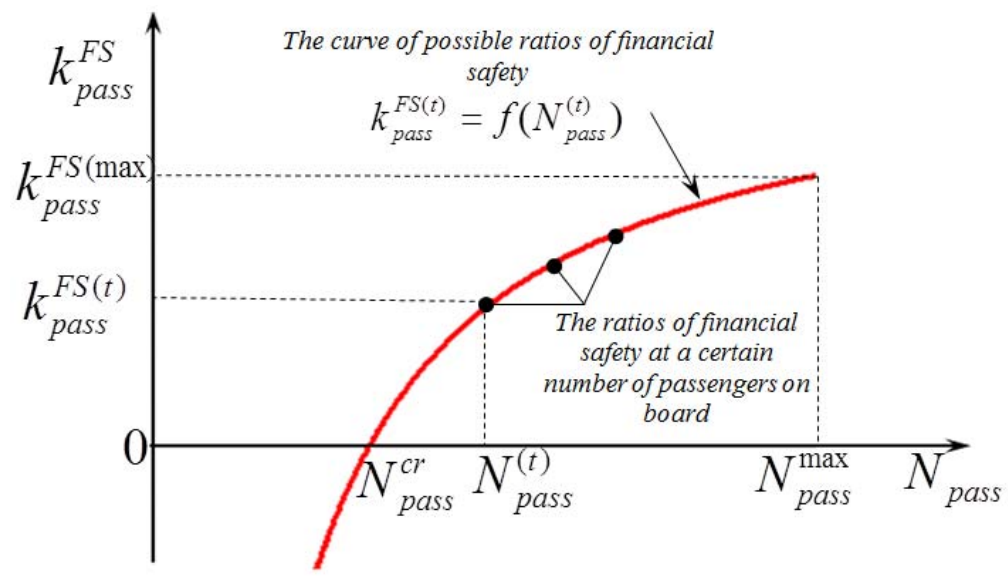

Figure 2. The ratio of financial safety when transporting the passengers, determined through the quantity of sold tickets, $\%$

Each point of the curve expresses the proportion to which company can reduce the amount of passenger transportation services so that it does not incur losses. That is, when reducing the amount of the sold tickets equal to $\left(k_{\text {pass }}^{F S(t)} \cdot N_{\text {pass }}^{(t)}\right)$, the company will make a profit $\left(\operatorname{Pr}_{\text {pass }}\right)$ from the tickets sold equal to zero (Kirillova \& Meleshenko, 2013a). At $\left(N_{\text {pass }}=N_{\text {pass }}^{c r}\right)$ the ratio of financial safety is also equal to zero: $k_{\text {pass }}^{F S}=0$.

However, the mentioned formulas of calculating the indicators (11), (12) as well as their graphical interpretation (Fig. 1 and Fig. 2) do not take into account the possibility of composite vessel loading with various nomenclature of cargoes and passengers, which is not only widely practiced on cargo-andpassenger ferries, but is their specific feature. Consequently, the ratio of financial safety, when calculating break-even point in ferry operation, depends both on the amount of the transported cargoes and the number of the carried passengers.

It should be noted that the indicators of cargoes $\left(N_{i}\right)$ and passengers $\left(N_{\text {pass }}\right)$ loading are incommensurable, as in the first case the indicator $\left(N_{i}\right)$ is measured in units (in items, rarely in metric tons and cubic measures) of $\mathrm{i}^{\text {th }}$ nomenclature range and in other case the indicator $\left(N_{\text {pass }}\right)$ is measured in number of passengers. Therefore, the ratio of financial safety taking into account the composite loading of the vessel is proposed to be calculated through the value of income which is measured in the same units as cargo loading and passenger loading.

Thus, the formula for calculating the ratio of financial safety when calculating break-even point in ferry operation can be represented as follows (13).

$k^{F S}=\frac{\left(\left(F_{i}+F_{\text {pass }}\right)-\left(F_{i}^{c r}+F_{\text {pass }}^{c r}\right)\right)}{\left(F_{i}+F_{\text {pass }}\right)} \cdot 100 \%\left(\right.$ at $\left.F_{i}+F_{\text {pass }} \neq 0\right)$.

At the same time it should be pointed out that income received from both cargoes $\left(F_{i}\right)$ and passengers' $\left(F_{\text {pass }}\right)$ transportation depends on the quantity of transporting cargoes and passengers, accordingly. In its turn, the critical volume of income received from cargoes $\left(F_{i}^{c r}\right)$ and passengers' $\left(F_{\text {pass }}^{c r}\right)$ transportation depends on the respective indicators of critical cargoes $\left(N_{i}^{c r}\right)$ and passengers' 
$\left(N_{\text {pass }}^{c r}\right)$ vessel loading. As mentioned above, these indicators $\left(N_{i}^{c r}\right)$ and $\left(N_{\text {pass }}^{c r}\right)$ are dynamic when composite loading of cargo and passengers and their volume and quantity are defined in each step $t$. Thus, the formula (13) can be expressed as follows (14).

$$
k^{F S(t)}=\frac{\left(\left(N_{i}^{(t)} \cdot f_{i}+N_{\text {pass }}^{(t)} \cdot f_{\text {pass }}\right)-\left(N_{i}^{c r(t)} \cdot f_{i}+N_{\text {pass }}^{c r(t)} \cdot f_{\text {pass }}\right)\right)}{\left(N_{i}^{(t)} \cdot f_{i}+N_{\text {pass }}^{(t)} \cdot f_{\text {pass }}\right)} \cdot 100 \% .
$$

In addition, taking into account the afore-said, when the indicator $N_{i}^{c r(t)}$ is expressed through $N_{\text {pass }}^{(t)}$ and the indicator $N_{\text {pass }}^{k p(t)}$ is expressed through $N_{i}^{(t)}$, the formula (14) can be presented in the form of equations (15) and (16), respectively.

$$
\begin{aligned}
& k^{F S(t)}=\frac{\left(\left(N_{i}^{(t)} \cdot f_{i}+N_{\text {pass }}^{(t)} \cdot f_{\text {pass }}\right)-\left(\frac{R_{\text {fix }}-N_{\text {pass }}^{(t)} \cdot\left(f_{\text {pass }}-r_{\text {pass }}\right)}{f_{i}-r_{i}} \cdot f_{i}+N_{\text {pass }}^{(t)} \cdot f_{\text {pass }}\right)\right)}{\left(N_{i}^{(t)} \cdot f_{i}+N_{\text {pass }}^{(t)} \cdot f_{\text {pass }}\right)} \cdot 100 \% ; \\
& k^{F S(t)}=\frac{\left(\left(N_{i}^{(t)} \cdot f_{i}+N_{\text {pass }}^{(t)} \cdot f_{\text {pass }}\right)-\left(N_{i}^{(t)} \cdot f_{i}+\frac{R_{\text {fix }}-N_{i}^{(t)} \cdot\left(f_{i}-r_{i}\right)}{f_{\text {pass }}-r_{\text {pass }}} \cdot f_{\text {pass }}\right)\right)}{\left(N_{i}^{(t)} \cdot f_{i}+N_{\text {pass }}^{(t)} \cdot f_{\text {pass }}\right)} \cdot 100 \% .
\end{aligned}
$$

Consequently, the ratio of financial safety is expressed by the function of two arguments: $k^{F S(t)}=f\left(N_{i}^{(t)}, N_{\text {pass }}^{(t)}\right)$. The graphic of this function is a surface, illustrated in three-dimensional space. Therefore, visualizing graphically the task of justification of critical cargo-and-passenger ferry loading, it is reasonable to use a right-handed three-dimensional coordinate system (Fig. 3), formed by mutually perpendicular axes:

- by $\mathrm{X}$-axis - $O X$, corresponding to the axis $O N_{i}$ in this case;

- by $\mathrm{Y}$-axis - $O Y$, corresponding to the axis $O k^{F S}$;

- by Z-axis $-O Z$, corresponding to the axis $O N_{\text {pass }}$.

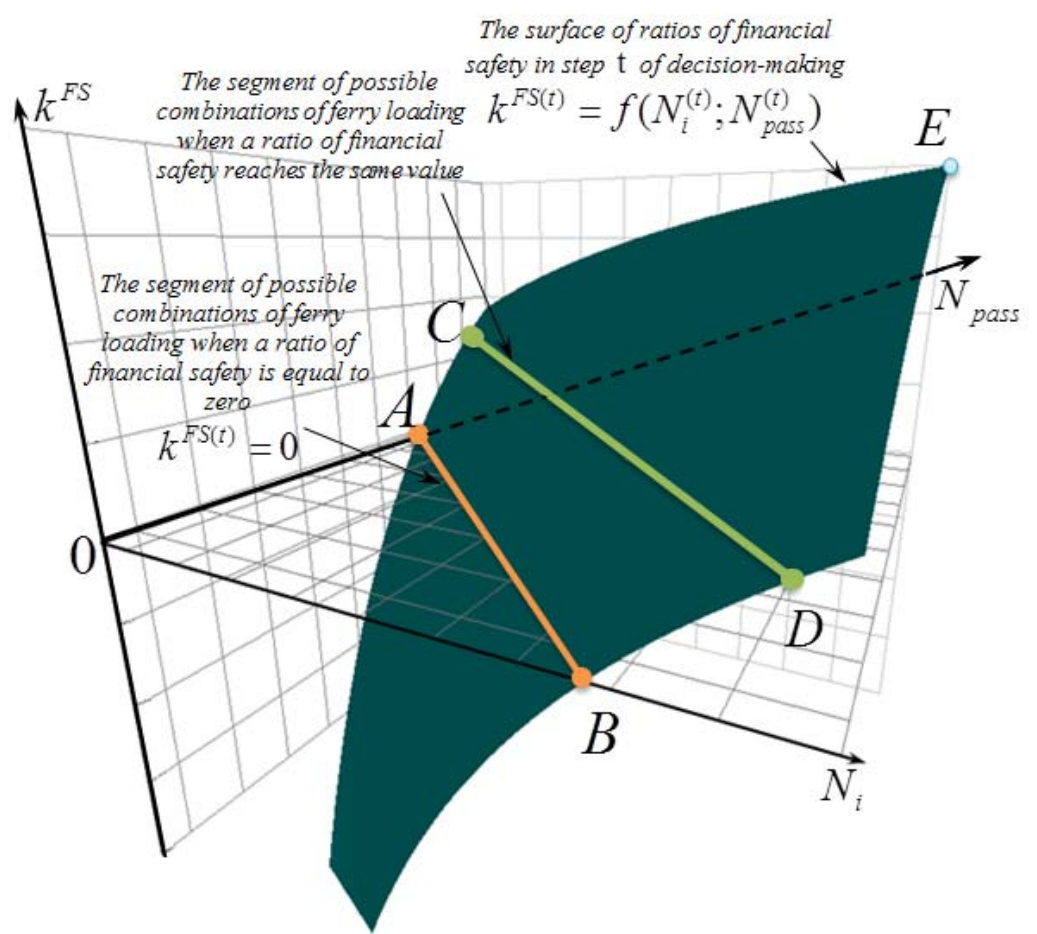

Figure 3. The graphical visualization of the task of determination of the ratio of financial safety of a cargo-and-passenger ferry 
The three-dimensional analysis of graphic (Fig. 3) visually shows that the break-even ferry loading, i.e. the loading at zero ratio of financial safety is reflected by segment $A B$ over which the surface given by function $k^{F S(t)}=f\left(N_{i}^{(t)} ; N_{\text {pass }}^{(t)}\right.$ ) and the plane formed by axes $0 ; N_{i}$ and $0 ; N_{\text {pass }}$ are crossed. It means that break-even cargo-and-passenger ferry loading may have a number of variants; each of them is reflected by a certain point lying on segment $A B$ (Fig. 3). The place of position of each point depends on proportion of parameters $N_{i}^{(t)}$ and $N_{\text {pass }}^{(t)}$ in step $\mathrm{t}$ of decision-making. In other words, the point, lying on this segment and reflecting the value of critical cargo-and-passenger ferry loading, moves along the segment depending on stept of decision-making and quantitative combination of cargoes $\left(N_{i}^{(t)}\right)$ and passengers $\left(N_{\text {pass }}^{(t)}\right)$ in ferry loading.

As it is known, each point in three-dimension space has coordinates $(X ; Y ; Z)$. In the concerned case (Fig. 3) each point of ratio of financial safety when loading the ferry both with cargoes and passengers in step $\mathrm{t}$ of decision-making is characterized by coordinates $\left(N_{i}^{t} ; k^{F S(t)} ; N_{\text {pass }}^{t}\right)$ and belongs to the surface expressed by function $f\left(N_{i}^{(t)} ; N_{\text {pass }}^{(t)}\right)$. Obviously, as well as in case of break-even ferry loading (Kirillova \&Meleshenko, 2013c) the ratio of financial safety may reach the same value at different combinations of cargoes $\left(N_{i}^{(t)}\right)$ and passengers $\left(N_{\text {pass }}^{(t)}\right)$ in the ferry loading. For each value of $k^{F S(t)}$ this combination may be graphically presented in the form of segment $C D$ (Fig. 3) corresponding to the following conditions:

- the segment $C D$ is parallel to the surface formed by axes $0 ; N_{i}$ and $0 ; N_{\text {pass }}\left(C D \| 0 N_{i} N_{\text {pass }}\right)$;

- the segment $C D$ belongs to the surface expressed by function $f\left(N_{i}^{(t)} ; N_{\text {pass }}^{(t)}\right)\left(C D \in f\left(N_{i}^{(t)} ; N_{\text {pass }}^{(t)}\right)\right)$.

The maximum value of ratio of financial safety is reached in point $E$ (Fig. 3) with coordinates $\left(N_{i}^{\max } ; k^{F S(\max )} ; N_{\text {pass }}^{\max }\right)$.

The usage of theoretical and methodical positions in the production activity of shipping companies when realizing the analysis function of cargo-and-passenger ferry operation and the graphical visualization of such analysis results enable:

- to define the values of ratio of financial safety in each step $t$ of decision-making subject to updating the information about the quantity of cargoes declared for transportation $\left(N_{i}^{(t)}\right)$ and about the number of sold tickets $\left(N_{\text {pass }}^{(t)}\right)$;

- to justify possible (typical) variants of ferry loading with cargoes $\left(N_{i}^{(t)}\right)$ and passengers $\left(N_{\text {pass }}^{(t)}\right)$, at which the standard (e.g. 10\%) value of ratio of financial safety determined by DM is being reached;

- to reveal possible variants of critical ferry loading with cargoes $\left(N_{i}^{(t)}\right)$ and passengers $\left(N_{\text {pass }}^{(t)}\right)$ at which the ratio of financial safety is equal to zero.

The application of the achieved results of analysis when managing the ferry operation allows making the decisions relating to:

- the determination of quantity of cargoes and/or passengers, which must be involved in transportation;

- ascertaining the share by which the value of transport services of cargo and passengers transportation may be reduced;

- the justification of value of reduction in the tariff for cargo transportation and, respectively, to the determination of the sum by which the passenger ticket cost may be reduced so that the ferry company takes profit and in case of unfavourable market situation does not incur losses.

\section{Conclusions}

As a result of research:

1. The dynamic indicators of critical cargo-and-passenger ferry loading have been determined. 
2. The process of justification of dynamic indicators of critical quantity of cargoes $\left(N_{i}^{c r(t)}\right)$ and passengers $\left(N_{\text {pass }}^{c r(t)}\right)$ in cargo-and-passenger ferry loading has been formalized.

3. The ratio of financial safety when calculating break-even point in ferry operation has been ascertained.

4. The process of justification of ratio of financial safety in case of the composite ferry loading with cargoes and passengers $\left(k^{F S(t)}\right)$ in each step $t$ of updating the information about quantity of cargo declared for transportation $\left(N_{i}^{(t)}\right)$ and number of sold tickets $\left(N_{\text {pass }}^{(t)}\right)$ has been formalized.

5. The graphical visualization of task of determination of cargo-and-passenger ferry' ratio of financial safety has been presented.

6. The usage of the introduced theoretical and methodical positions when analysing the cargoand-passenger ferry operation, as well as a graphical visualization of the results of such analysis enables to make effective management decisions that ensure Ferry Company to make a profit, and in case of unfavourable market conditions they help to avoid losses.

In general, the theoretical and methodical aspects proposed and formulated in the research contribute to the improvement of the analysis of the cargo-and-passenger ferry operation, and applying the results of the procedure described above enables to make the efficient management decisions when planning and regulating the ferry operation.

\section{References}

1. Kirillova, Ye.V., Kirillov, Yu.I. (2008). Formalization and systematization of critical and optimal values of the vessel parameters, Methods and tools for management of development of transport systems, 13, 165-198.

2. Vinnicov, V.V. (2001). The economy of marine transport company. Odessa: Latstar. 416 p.

3. Soyuzov, A.A., Dubinskiy, P.R., Condrushkin, O.T. \& Petuhov, V.S. (1979). The organization and planning of marine fleet operation. Moscow: Transport. $416 \mathrm{p}$.

4. Bakayev, V.G. (1965). The operation of marine fleet. Moscow: Transport. $560 \mathrm{p}$.

5. Kirillova, Ye.V. (2007). The system of indicators of commercially reasonable vessel loading, The bulletin of Odessa National Maritime University, 22, 54-68.

6. Kirillova, Ye.V., Meleshenko, Ye.S. (2012). The indicators of critically break-even and commercially reasonable operation of cruise company. In The collection of scientific papers SWorld; The prospective innovations in science, education, manufacturing and transport, Odessa, Ukraine, June 19-30, 2013 (pp. 54-58). Odessa: CUPRIENCO.

7. Kirillova, Ye.V. (2006). The justification of optimal quantity of cargoes in the vessel loading, Methods and Tools for Management of Development of Transport Systems, 11, 142-153.

8. Kirillova, Ye.V., Meleshenko, Ye.S. (2013a). The analytical method of justification of critical cargo-and-passenger ferry loading. In: The collection of scientific papers SWorld; The modern directions of theoretical and applied researches, Odessa, Ukraine, March 19-30, 2013 (pp. 64-67). Odessa: CUPRIENCO.

9. Kirillova, Ye.V., Meleshenko, Ye.S. (2013b). The dynamic indicators of critical and commercially reasonable loading of cargo-and-passenger ferry, The bulletin of Odessa National Maritime University, 38, 72-95.

10. Kirillova, Ye.V., Meleshenko, Ye.S. (2013c). The dynamic indicators of critical cargo-and passenger ferry operation, The Marine Transport, 16, 36-42.

11. Stoyanova, Ye.S. (2003). The financial management: theory and practice. Moscow: Perspective. $656 \mathrm{p}$. 